Check for updates

Cite this: RSC Adv., 2018, 8, 22944

\title{
Palladium-catalyzed tandem allylic substitution/ cyclization and cascade hydrosilylated reduction: the influence of reaction parameters and hydrosilanes on the stereoselectivity $\dagger$
}

\author{
Peng-Wei Long, ${ }^{a}$ Jian-Xing $\mathrm{Xu},{ }^{a}$ Xing-Feng Bai, ${ }^{a b}$ Zheng Xu, ${ }^{\text {*a }}$ Zhan-Jiang Zheng, ${ }^{a}$ \\ Ke-Fang Yang, ${ }^{a} \mathrm{Li} \mathrm{Li}^{\mathrm{a}}$ and Li-Wen Xu (D) *ab \\ To shed light on the influence of reaction parameters on palladium-catalyzed tandem allylic alkylation in the \\ presence of Fei-Phos (a chiral trans-1,2-diaminocyclohexane-derived phosphine ligand), the effect of \\ different phosphine ligands, inorganic or organic bases, Brønsted acids, and other additives on the \\ asymmetric palladium-catalysed alkylation of catechol with allylic diacetate was investigated. In this \\ reaction, 2-vinyl-2,3-dihydro-benzo[1,4]dioxin products with promising enantioselectivity were achieved \\ in good yields. In addition, a novel palladium-catalyzed three-component and one-pot allylic \\ substitution/cyclization/reduction reaction assisted by methylphenylsilane was reported with good \\ selectivity.
}

Received 8th April 2018

Accepted 12th June 2018

DOI: $10.1039 / \mathrm{c} 8 \mathrm{ra02995d}$

rsc.li/rsc-advances reactivity substrates for catalytic asymmetric allylic substitution reactions with improved activity and stereoselectivity. Despite the recent success in allylic alkylation of various carbon- or heteroatom-based nucleophiles, including cyanoacetate, alcohols, and heterocycles, ${ }^{6}$ transition-metal-catalyzed asymmetric allylic substitutions of functional molecules with structurally varied allylic acetates continue to receive much attention from synthetic chemists. Thus the development of new reaction systems with good yields and stereoselectivity is a valuable topic and is still highly desirable.

Among allylic substitution reactions, the stereoselective allylic alkylation of oxygen-nucleophiles, such as alcohols, is one of the most important $\mathrm{C}-\mathrm{O}$ bond-forming transformations for the construction of chiral ether-containing compounds. ${ }^{7}$ Notably, in this context, palladium complexes with bidentate phosphine or phosphite ligands have been proven to be effective catalysts for the construction of different $\mathrm{C}-\mathrm{O}$ bonds and chiral ethers with good stereoselectivity. ${ }^{7}$ For example, we developed the chiral trans-1,2-diaminocyclohexane-derived multiple stereogenic and multifunctional CycloN2P2-Phos (also called Fei-Phos) for catalytic asymmetric allylic substitutions of benzyl alcohols and silanols with allylic acetates. ${ }^{8}$ Good to excellent yields and high enantioselectivities (up to $99 \%$ ee) were achieved in this reaction, which motivated us to expand the synthetic functions of Fei-Phos in palladium catalysis. ${ }^{9}$ Although asymmetric palladium-catalyzed allylic alkylation of catechol with (Z)-2-butene-1,4-diylbis(methylcarbonate) gave the desired 2-vinyl-1,4-benzodioxane with up to $45 \%$ ee in the presence of chiral ligands such as BINAP was realized by Sinou in $1994,{ }^{10}$ the use of simple allylic acetates as the electrophiles
${ }^{a}$ Key Laboratory of Organosilicon Chemistry and Material Technology of Ministry of Education, Hangzhou Normal University, Hangzhou 311121, P. R. China. E-mail: liwenxu@hznu.edu.cn; Fax: +86 2886 5135; Tel: +86 28865135

${ }^{b}$ State Key Laboratory for Oxo Synthesis and Selective Oxidation, Lanzhou Institute of Chemical Physics, Chinese Academy of Sciences, Lanzhou 730000, P. R. China. E-mail: licpxulw@yahoo.com

$\dagger$ Electronic supplementary information (ESI) available. See DOI: $10.1039 / \mathrm{c} 8 \mathrm{ra02995d}$ 
in this reaction has not been described yet. In addition, it is surprising that limited progress has been made so far on the tandem allylic alkylation of catechol with allylic reagents for the synthesis of chiral 2-vinyl-2,3-dihydro-benzo[1,4]dioxanes. ${ }^{11}$ Thus in this work, we continue to carry out further investigations on the catalytic asymmetric allylic substitution of catechol with allylic diacetates in the presence of a palladium catalyst with Fei-Phos or other P-ligands. This approach could be useful for the construction of 1,4-benzodioxane ring systems that are found in various natural products and are key skeletons in pharmaceutical candidates possessing important biological activities. ${ }^{12}$ In addition, the effect of various phosphine ligands, inorganic or organic bases, Brønsted acids, and other additives, on the asymmetric palladium-catalysed alkylation of catechol with allylic diacetate was investigated in this work.

\section{Results and discussion}

\section{Palladium-catalyzed tandem allylic alkylation of catechol with} allylic compounds

Firstly, the allylic substitution/cyclization reaction of benzene1,2-diol 19 with the (Z)-but-2-ene-1,4-diol-derived allylic acetate $2 \mathbf{a}$ was used as a model reaction at room temperature in the presence of a palladium complex which was generated in situ by mixing $\operatorname{Pd}_{2}(\mathrm{dba})_{3}$ [tris(benzylideneacetone)dipalladium] with various phosphine ligands (Scheme 1). It should be noted that there is no effective phosphine ligand previously reported for this reaction. ${ }^{\mathbf{1 0 , 1 1}}$ To evaluate the feasibility of the tandem allylic alkylation reactions, we wanted to explore the potential of commercially available phosphine ligands and our P-ligands, which we have reported in the past few years, ${ }^{13}$ including FeiPhos. Results from the optimization studies employing the

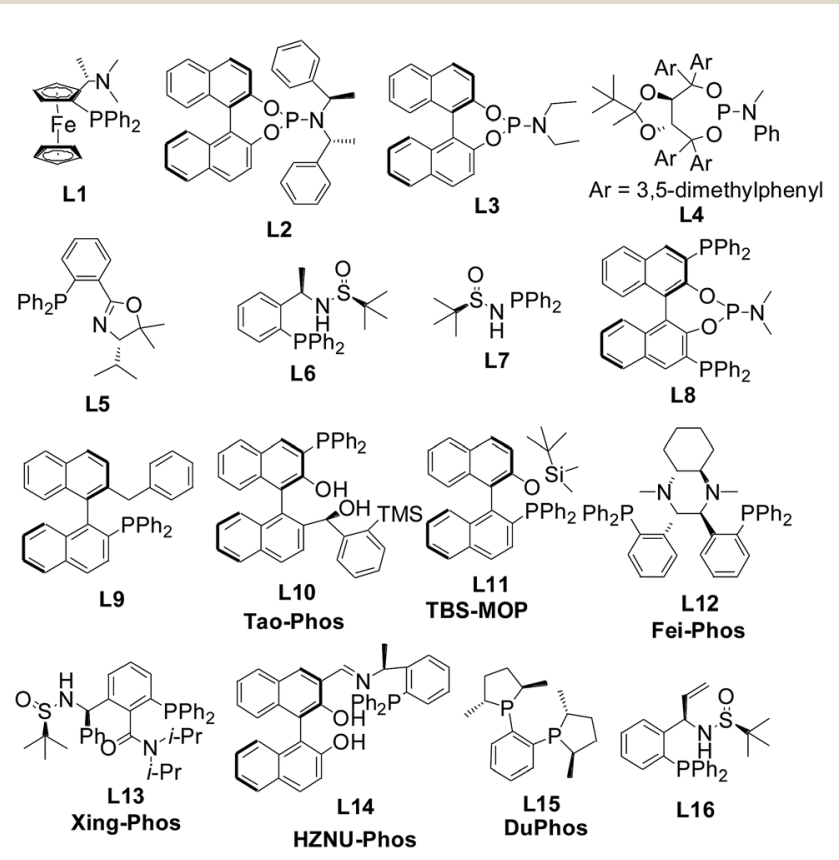

Scheme 1 The various phosphine ligands evaluated in the palladiumcatalyzed tandem allylic alkylation of benzene-1,2-diol 1a with the (Z)but-2-ene-1,4-diol derived allylic acetate $2 \mathrm{a}$. phosphine ligands are summarized in Table 1 . Notably, most of the phosphine ligands gave poor or no yield of the corresponding product 3a. Only L3, L8, and L12 (Fei-Phos) were proven to be effective in this reaction (entries 3, 8, and 12, respectively), and $\mathbf{L} 3$ and $\mathbf{L 8}$ gave low to moderate yields (30$50 \%$ ) as well as low enantioselectivity (25-39\% ee). Interestingly, our Fei-Phos is still the best choice in this reaction in comparison with the other P-ligands evaluated in this work (entry 12, 60\% yield and 39\% ee). Notably, when the reaction temperature was decreased to 0 or $-20{ }^{\circ} \mathrm{C}$, both the yield and enantioselectivity decreased obviously (entries 17 and 18). With the optimized ligand in THF, the solvent effect was also evaluated in the catalytic asymmetric allylic substitution/cyclization reaction (Table 1, entries 19-22). Although this tandem allylic substitution reaction occurred smoothly to deliver 2-vinyl-2,3dihydro-benzo[1,4]dioxane (3a) with good yields (70\%) in 1,4dioxane, the solvents evaluated in this work gave inferior performance in comparison with THF.

Then, we continued to investigate the effect of the palladium catalyst precursors or other transition metal catalysts on the

Table 1 The effect of the various phosphine ligands on the palladiumcatalyzed allylic substitution/cyclization reaction of benzene-1,2-diol $1 \mathrm{a}$ with the (Z)-but-2-ene-1,4-diol derived allylic acetate $2 \mathrm{a}$

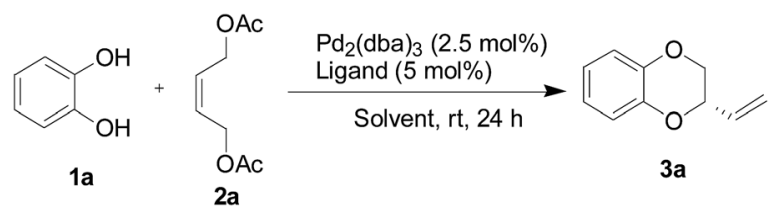

\begin{tabular}{|c|c|c|c|c|}
\hline Entry $^{a}$ & Ligand & Solvent & Yield $^{d}(\%)$ & $\mathrm{ee}^{e, f}(\%)$ \\
\hline 1 & L1 & $\mathrm{THF}$ & n.r & - \\
\hline 2 & L2 & $\mathrm{THF}$ & $<5$ & - \\
\hline 3 & L3 & $\mathrm{THF}$ & 50 & 39 \\
\hline 4 & L4 & $\mathrm{THF}$ & n.r & - \\
\hline 5 & $\mathbf{L 5}$ & $\mathrm{THF}$ & n.r & - \\
\hline 6 & L6 & $\mathrm{THF}$ & n.r & - \\
\hline 7 & L7 & $\mathrm{THF}$ & n.r & - \\
\hline 8 & L8 & $\mathrm{THF}$ & 30 & 25 \\
\hline 9 & L9 & $\mathrm{THF}$ & n.r & - \\
\hline 10 & L10 & THF & n.r & - \\
\hline 11 & L11 & THF & n.r & - \\
\hline 12 & L12 & $\mathrm{THF}$ & 60 & 39 \\
\hline 13 & L13 & THF & n.r & - \\
\hline 14 & L14 & THF & n.r & - \\
\hline 15 & L15 & THF & n.r & - \\
\hline 16 & L16 & THF & n.r & - \\
\hline $17^{b}$ & L12 & $\mathrm{THF}$ & 24 & 31 \\
\hline $18^{c}$ & L12 & $\mathrm{THF}$ & 5 & 33 \\
\hline 19 & L12 & 1,4-Dioxane & 72 & 35 \\
\hline 20 & L12 & DCM & $<5$ & - \\
\hline 21 & L12 & DCE & 12 & n.d \\
\hline 22 & L12 & DMSO & n.r & - \\
\hline
\end{tabular}

${ }^{a}$ Reaction conditions: $1 \mathrm{a}(0.25 \mathrm{mmol}), \mathbf{2 a}(1.4 \mathrm{eq}),. \mathrm{Pd}_{2}(\mathrm{dba})_{3}(2.5 \mathrm{~mol} \%)$ and Fei-Phos ( $5 \mathrm{~mol} \%), \mathrm{N}_{2}$, rt, $24 \mathrm{~h} .{ }^{b}$ The temperature was $0{ }^{\circ} \mathrm{C} .{ }^{c}$ The temperature was $-20{ }^{\circ} \mathrm{C}$. ${ }^{d}$ Isolated yields after silica gel chromatography. ${ }^{e}$ Determined using chiral HPLC. n.r is no reaction; a trace is represented by $<5 \%$ yield; n.d is not determined. ${ }^{f}$ Determined by the sign of the specific rotation. ${ }^{14}$ 
catalytic asymmetric allylic alkylation. As shown in Table 2, most of the palladium salts were not suitable for this tandem allylic alkylation reaction, in which only $\left[\mathrm{Pd}\left(\eta-\mathrm{C}_{3} \mathrm{H}_{5}\right) \mathrm{Cl}\right]_{2}$ and $\mathrm{Pd}\left(\mathrm{PPh}_{3}\right)_{4}$ had the ability to promote tandem allylic substitution to give the corresponding 2-vinyl-2,3-dihydro-benzo[1,4]dioxane (3a) in moderate yield (35-58\%). Interestingly, other palladium salts or transition metal salts, such as $\mathrm{PdCl}_{2}\left(\mathrm{CH}_{3} \mathrm{CN}\right)_{2}$, $\mathrm{Pd}(\mathrm{OAc})_{2},[\mathrm{RhCl}(\mathrm{cod})]_{2},[\operatorname{Ir}(\operatorname{cod}) \mathrm{OMe}]_{2}$, or $\mathrm{RuCl}(\mathrm{PPh})_{3}$, were not suitable catalyst precursors in this reaction. These experimental results showed that the enhancement of enantioselectivity in the palladium-catalyzed allylic substitution/cyclization reaction of benzene-1,2-diol 1a with the (Z)-but-2-ene-1,4-diol derived allylic acetate $\mathbf{2 a}$ is not an easy task. The major reason possibly originated in the acidity of catechol because we have found that the equilibrium acidity $\left(\mathrm{p} K_{\mathrm{a}}\right)$ is an important factor in the reactivity of structurally diverse alcohols. ${ }^{9}$

Therefore, on the basis of the above findings, the modification of the reaction parameters by the addition of acidic or basic additive to tune the acidity is not trivial in this work. Initially, the Pd/Fei-Phos-catalyzed tandem allylic substitution of benzene-1,2-diol 1a with the (Z)-but-2-ene-1,4-diol derived allylic acetate $2 \mathrm{a}$ was carried out in the presence of various inorganic bases or organic bases at room temperature. As shown in Fig. 1, the effect of the bases on the enantioselectivity in the palladium/Fei-Phos catalyzed allylic substitution/ cyclization reaction provided direct information that this reaction largely relied on the acidity of the reaction system (Table S6 of ESI†). For example, when $\mathrm{KF}$ or $\mathrm{Na}_{2} \mathrm{CO}_{3}$ was used as the base,

Table 2 The effect of palladium salts or other transition metal salts on the catalytic asymmetric allylic alkylation of benzene-1,2-diol 1a with the (Z)-but-2-ene-1,4-diol derived allylic acetate $2 \mathrm{a}$ in the presence of Fei-Phos

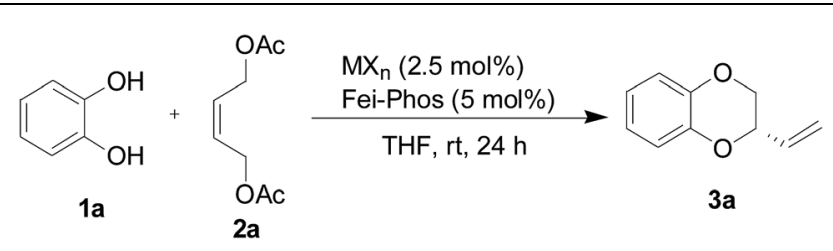

\begin{tabular}{llll}
\hline Entry $^{a}$ & Catalyst & Yield $^{b}(\%)$ & ee $^{c}(\%)$ \\
\hline 1 & {$\left[\mathrm{Pd}\left(\mathrm{C}_{3} \mathrm{H}_{5}\right) \mathrm{Cl}\right]_{2}$} & 58 & 35 \\
2 & $\left(\mathrm{Ph}_{3} \mathrm{P}\right)_{4} \mathrm{Pd}$ & 35 & 19 \\
3 & $\mathrm{PdCl}_{2}\left(\mathrm{CH}_{3} \mathrm{CN}\right)_{2}$ & n.r & - \\
4 & $\mathrm{PdCl}_{2}\left(\mathrm{PhCN}_{2}\right.$ & $<5$ & - \\
5 & $\mathrm{Pd}(\mathrm{OAc})_{2}$ & n.r & - \\
6 & $\mathrm{RhCl}\left(\mathrm{PPh}_{3}\right)$ & n.r & - \\
7 & {$[\mathrm{RhCl}(\mathrm{coe})]_{2}$} & n.r & \\
8 & {$[\mathrm{RhCl}(\mathrm{cod})]_{2}$} & n.r & \\
9 & {$[\mathrm{RhCl}(\mathrm{pmcpd})]_{2}$} & n.r & \\
10 & $\mathrm{RuCl}(\mathrm{PPh})_{3}$ & n.r & \\
11 & {$[\operatorname{Ir}(\operatorname{cod}) \mathrm{OMe}]_{2}$} & n.r &
\end{tabular}

${ }^{a}$ Reaction conditions: the reaction of $1 \mathrm{a}(0.25 \mathrm{mmol})$ and $2 \mathrm{a}$ (1.4 eq.) was carried out under $\mathrm{N}_{2}$ at room temperature for $24 \mathrm{~h}$ by mixing with [Pd] (5 mol\%), [Rh] (5 mol\%), [Ru] (5 mol\%), or [Ir] (5 mol\%) and the chiral ligand $(5 \mathrm{~mol} \%)$. ${ }^{b}$ Isolated yields after silica gel chromatography. ${ }^{c}$ Determined using chiral HPLC.
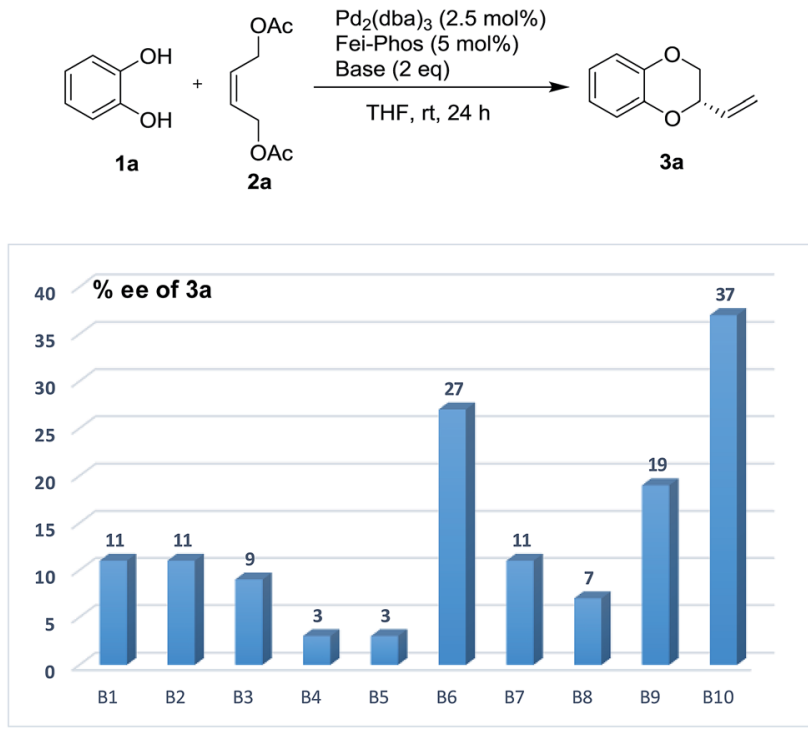

Fig. 1 The effect of base (B1-B10) on the enantioselectivity in the Pdcatalyzed tandem allylic substitution/cyclization: $\mathrm{B} 1\left(\mathrm{~K}_{2} \mathrm{CO}_{3}\right), \mathrm{B} 2$ $\left(\mathrm{KHCO}_{3}\right), \mathrm{B} 3\left(\mathrm{~K}_{3} \mathrm{PO}_{4}\right), \mathrm{B} 4(\mathrm{KF}), \mathrm{B} 5\left(\mathrm{Na}_{2} \mathrm{CO}_{3}\right), \mathrm{B} 6\left(\mathrm{NaHCO}_{3}\right), \mathrm{B} 7\left(\mathrm{Cs}_{2} \mathrm{CO}_{3}\right)$, $\mathrm{B} 8(\mathrm{DBU}), \mathrm{B} 9\left(\mathrm{Et}_{3} \mathrm{~N}\right)$ and $\mathrm{B} 10$ (DIPEA).

almost no enantioselectivity was observed and almost all the bases decreased the stereoselectivity (3-37\% ee).

Similarly, the effect of organic acids on the enantioselective Pd-catalyzed allylic alkylation was also performed under the optimized reaction conditions. As shown in Fig. 2, it was found that all the chiral organic acids, such as mandelic acid and proline, gave the desired product 3a with a low enantioselectivity (5-25\% ee). Interestingly, the absolute configuration of the chiral organic acid played important role in the influence of the additive, for example, $(S)-(+)$-mandelic acid or $\mathrm{L}-(-)$-proline gave higher enantioselectivity than $(R)-(-)$-mandelic acid or $\mathrm{D}-(-)$-proline. Although most of the organic acids had no ability to improve the enantioselectivity, the experimental results clearly supported the theory that the organic acids could affect the catalytic efficiency of the palladium catalyst in this reaction. Gratifyingly, among the different organic acids used as additives in this reaction, phenylboronic acid was determined to be an excellent additive for the enhancement of enantioselectivity.

As shown in Fig. 3, phenylboronic acid improved the enantioselectivity from $39 \%$ ee to $51 \%$ ee when $10 \mathrm{~mol} \%$ of $\mathrm{PhB}(\mathrm{OH})_{2}$ was used in this reaction. However, the yield was quite low in this case ( $10 \%$ isolated yield). Inspired by this finding, the role of various arylboronic acids in the palladium-catalyzed tandem allylic substitution of benzene-1,2-diol 1a with the ( $Z$ )-but-2-ene1,4-diol derived allylic acetate 2a was then investigated using a series of experimental studies. As shown in Table S7 (see the ESI $\dagger$ ) about 20 examples revealed that phenylboronic acid was still the best additive in this reaction.

Then the effect of the amount of phenylboronic acid on the enantioselectivity was further investigated. Unfortunately, it was difficult to exceed $51 \%$ ee when larger amounts of phenylboronic acid were used as the additive in the palladiumcatalyzed allylic substitution/cyclization reaction (Fig. 4). 

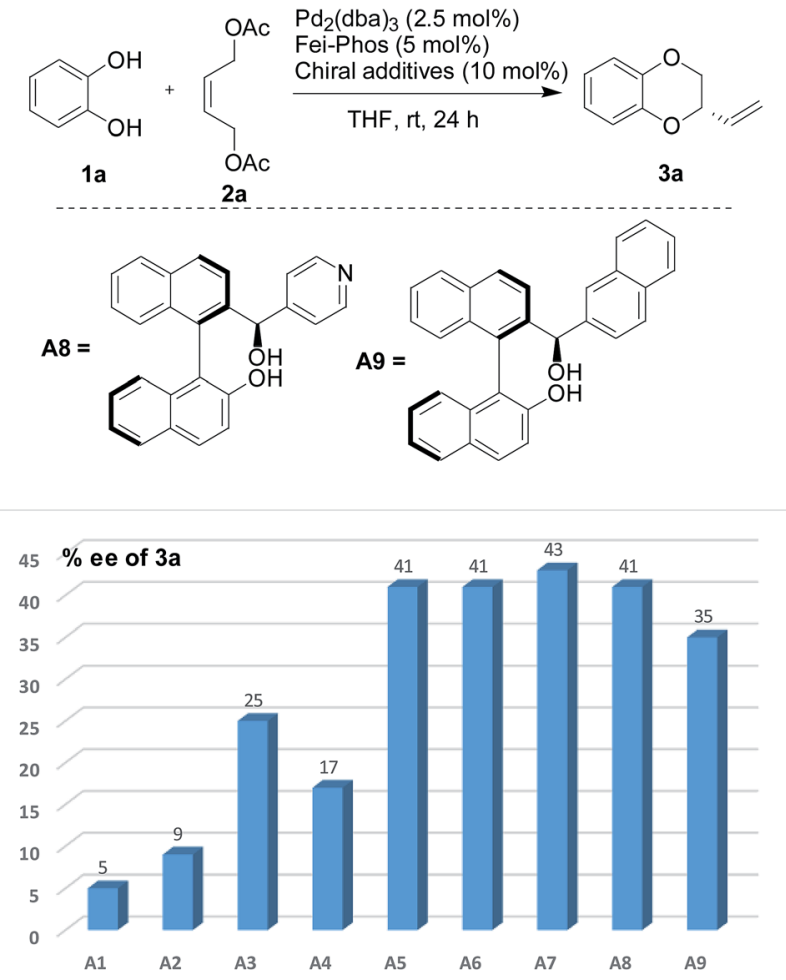

Fig. 2 The effect of chiral organic acids on the enantioselectivity in the Pd-catalyzed tandem allylic substitution/cyclization: A1 [(S)-(+)-mandelic acid], A2 [(R)-(+)-mandelic acid], A3 [L-(-)-proline], A4 [D-(+)-proline], A5 [(S)-BNIOL], A6 [(R)-BINOL], A7 (race-BINOL), A8, and A9. ${ }^{15}$

It is well-known that the leaving group is also an important factor in the palladium-catalyzed allylic alkylation reaction. ${ }^{\mathbf{1 1}}$ Thus its effect on the enantioselectivity of the allylic
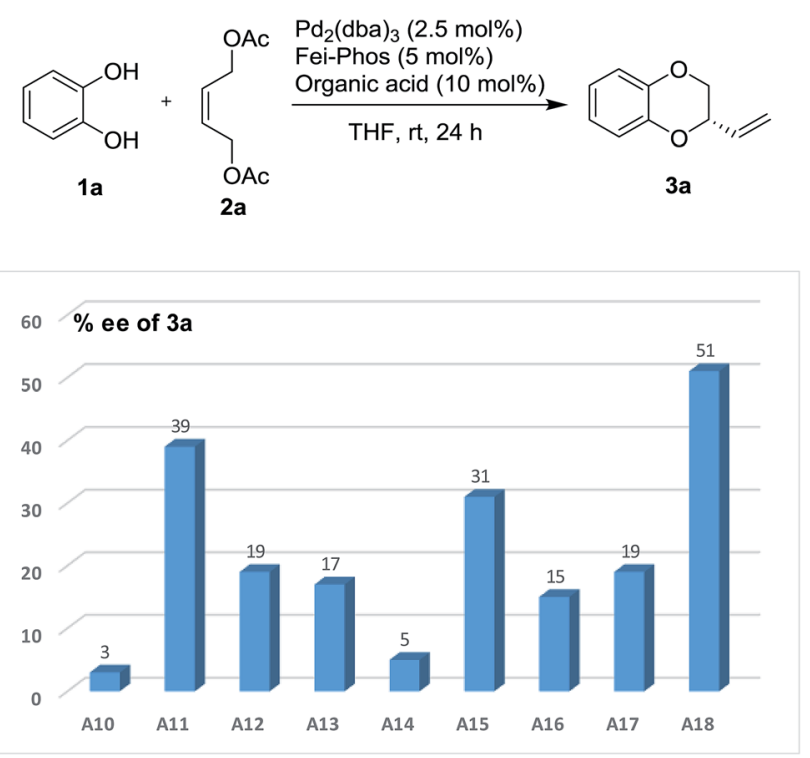

Fig. 3 The effect of organic acids on the enantioselectivity in the Pdcatalyzed tandem allylic substitution/cyclization: A10 (benzoic acid), A11 (2-methylbenzoic acid), A12 (abietic acid), A13 (ascorbic acid), A14 (pivalic acid), A15 (boric acid), A16 (cyclopropylboronic acid), A17 (2naphthaleneacetic acid) and A18 (phenylboronic acid).
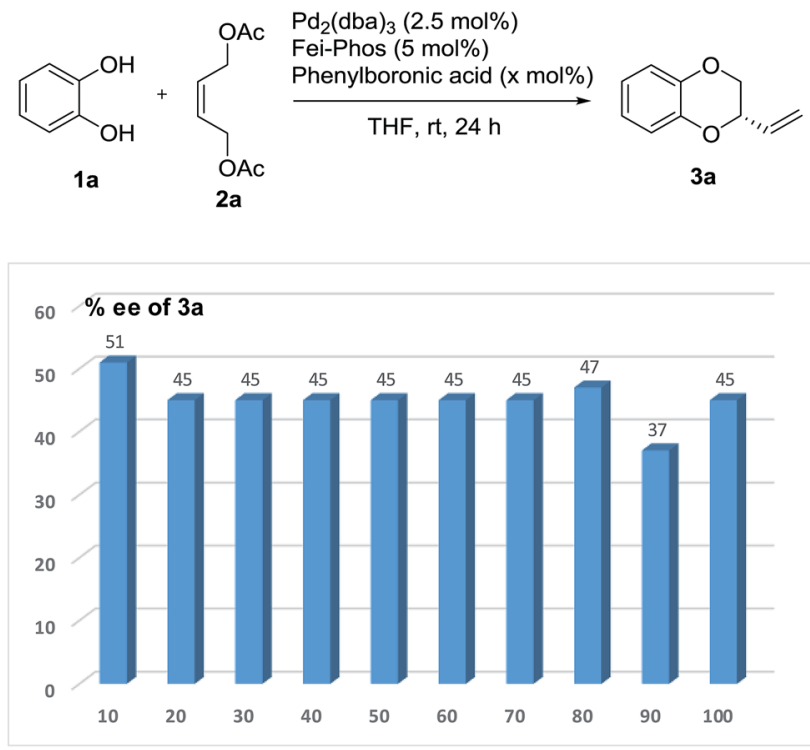

Fig. 4 The effect of the amount of phenylboronic acid on the enantioselectivity in the $\mathrm{Pd}$-catalyzed tandem allylic substitution/ cyclization.

substitution/cyclization reaction is shown in Fig. 5. The results indicate that the benzoyl group as the leaving group has the best enantioselectivity (45\% ee). In addition, the enantioselectivity due to the leaving group was influenced largely by whether it was an electron-donating group, for example, with a $p$ -
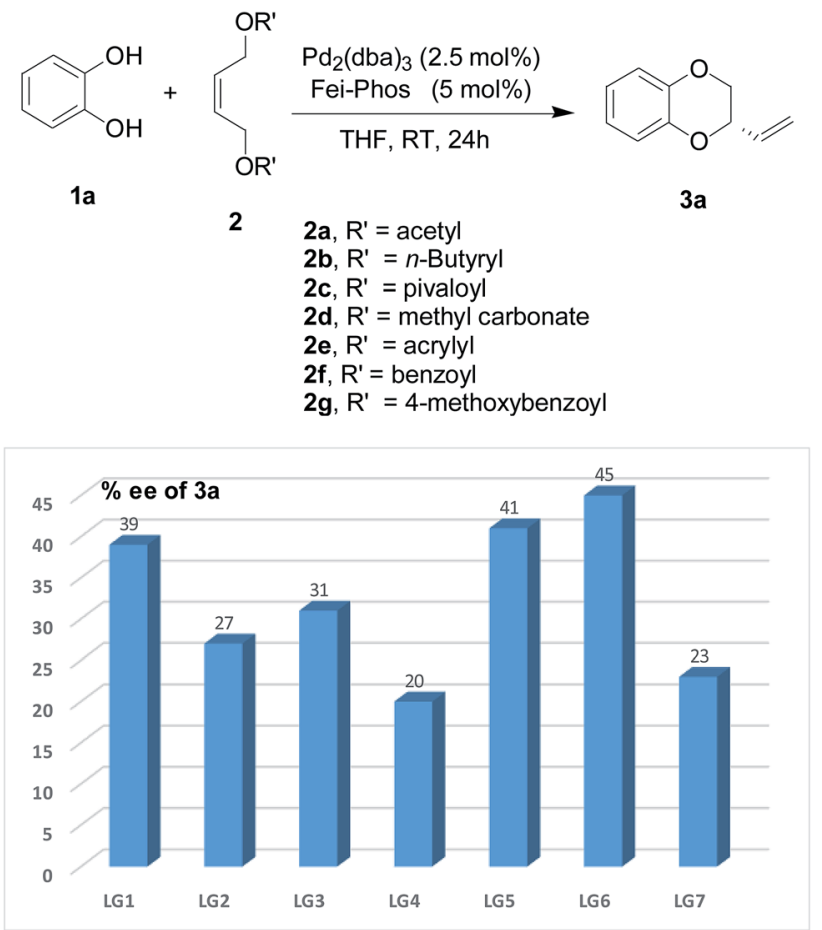

Fig. 5 The effect of the leaving group of substrate 2 on the enantioselectivity in the $\mathrm{Pd}$-catalyzed tandem allylic substitution/cyclization: LG1 (acetyl), LG2 (n-butyryl), LG3 (pivaloyl), LG4 (methyl carbonate), LG5 (acrylyl), LG6 (benzoyl) and LG7 (4-methoxybenzoyl). 


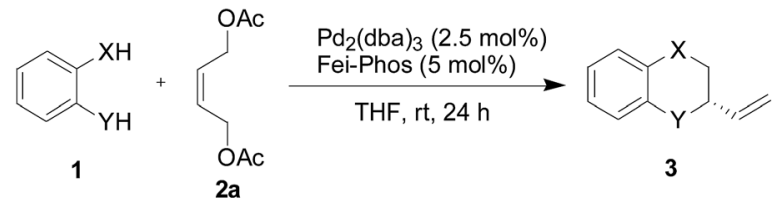

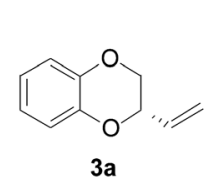

$60 \%$ yield, $39 \%$ ee

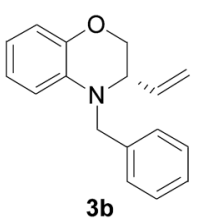

$90 \%$ yield, $35 \%$ ee

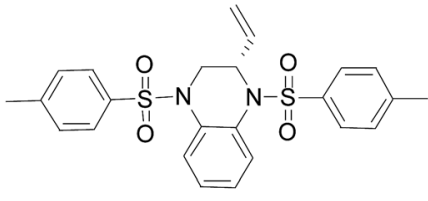

3d

$90 \%$ yield, $15 \%$ ee

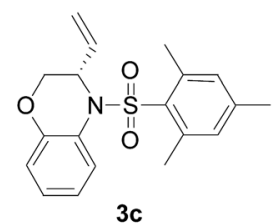

$67 \%$ yield, $7 \%$ ee

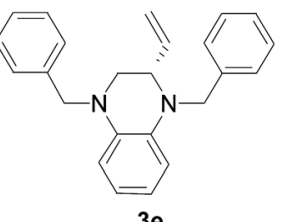

$70 \%$ yield, $27 \%$ ee
Scheme 2 Fei-Phos ligand-controlled palladium-catalyzed tandem allylic alkylation of different 1,2-bifunctional nucleophiles 1 with the (Z)-but-2-ene-1,4-diol derived allylic acetate $2 \mathrm{a}$ : a representative substrate scope.

methoxybenzyl group as the leaving group, the enantioselectivity of the reaction system reduced to $23 \%$ ee. However, other fatty acids and unsaturated fatty acids other than acetic acid esters had no significant enhancement on the enantioselectivity of the tandem allylic alkylation. Moreover, under the optimized reaction conditions, all these leaving groups decreased the yields to lower than that with the acetyl group.

Therefore, under the optimized reaction conditions shown in Table 1, we further investigated the substrate scope of the catalytic asymmetric tandem allylic substitution/cyclization reaction of different 1,2-bifunctional nucleophiles 1 with the (Z)-but-2-ene-1,4-diol derived allylic acetate 2a. As shown in Scheme 2, good yields and promising ee values were obtained for various substituted 2-heterocycles 3 (up to $7-39 \%$ ee). Although the enantioselectivity is not good enough, the present method is quite simple and features good yields. In addition, the reaction information described above provides a springboard to modify the reaction conditions of the palladiumcatalyzed tandem allylic alkylation reactions in the near future.

\section{Palladium-catalyzed three-component tandem allylic} substitution/cyclization and cascade hydrosilylated reduction

Encouraged by the experimental results for the palladiumcatalyzed tandem allylic alkylation of different 1,2-bifunctional nucleophiles 1 with the $(Z)$-but-2-ene-1,4-diol-derived allylic acetate 2a shown in Scheme 2, we turned our attention to the design of a novel one-pot multicomponent asymmetric allylic alkylation and cascade hydrosilylated reduction. In fact, we found that 2-vinyl-2,3-dihydro-benzo[1,4]dioxane (3a) and the other products 3 were not stable enough in the presence of the palladium catalyst. We proposed that the palladium- promoted isomerisation of the alkene group resulted in the deceased enantioselectivity. ${ }^{\mathbf{1 6}}$ Therefore, the reduction of the vinyl group by hydrosilane would be an interesting topic because the palladium complex associated with Fei-Phos would be effective in this reaction. However, to the best of our knowledge, despite the previous success of Pd-catalyzed tandem reactions, ${ }^{17}$ there are no past reports on a palladium-catalyzed cascade allylic alkylation/hydrosilylated reduction. In addition, the different activities of hydrosilanes makes this reaction quite difficult and unpredictable. Herein, with commercially available hydrosilanes to hand, including PMHS (polymethylhydrosiloxane), $\mathrm{Ph}_{2} \mathrm{SiH}_{2}, \mathrm{MePhSiH}_{2}, \mathrm{PhSiH}_{3}$, and $\mathrm{MePh}_{2} \mathrm{SiH}$, a one-pot palladiumcatalyzed asymmetric allylic alkylation and cascade hydrosilylated reduction reaction was attempted under optimized reaction conditions (see Table 3 and Table S10 in the ESI; $\uparrow 2.5 \mathrm{~mol} \%$ of palladium catalyst, $\mathrm{Pd}_{2}(\mathrm{dba})_{3}, 5 \mathrm{~mol} \%$ of Fei-Phos, and 3 equiv. hydrosilane in THF were determined as the optimal reaction conditions).

To our delight, the palladium catalyst with Fei-Phos was also highly effective in the asymmetric tandem allylic alkylation of benzene-1,2-diol 1a with the (Z)-but-2-ene-1,4-diol derived allylic acetate $\mathbf{2 a}$. The results presented in Table 3 clearly demonstrate the efficiency of Fei-Phos in this multicomponent allylic alkylation transformation. The corresponding product $\mathbf{4 a}$ could be obtained with varied yields with better enantioselectivity ( $45 \%$ ee), which supported our hypothesis that the direct reduction of 2-vinyl-2,3-dihydro-benzo[1,4]dioxane (3a) could inhibit the isomerization of the double carbon-carbon bond in this reaction. In particular, when $\mathrm{MePhSiH}_{2}$ was used as a reductive hydrosilane, only the desired product 4 a was obtained, while other hydrosilanes gave poor chemoselectivity or had no activity for the cascade hydrosilylated reduction.

Table 3 The activities of various hydrosilanes in the asymmetric palladium-catalyzed tandem allylic alkylation of benzene-1,2-diol 1a with the (Z)-but-2-ene-1,4-diol derived allylic acetate $2 \mathrm{a}$

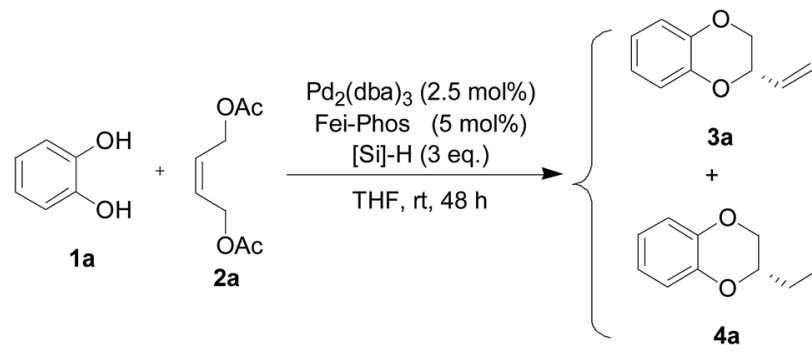

\begin{tabular}{llll}
\hline Entry $^{a}$ & Silane & Yield $^{b}(\%)$ & $\mathbf{3 a}: \mathbf{4 a}^{c}$ \\
\hline 1 & $\mathrm{PMHS}$ & $99 \%$ & $1: 0.48$ \\
2 & $\mathrm{Ph}_{2} \mathrm{SiH}_{2}$ & $99 \%$ & $1: 0.59$ \\
3 & $\mathrm{MePhSiH}_{2}$ & $99 \%$ & $0: 1$ \\
4 & $\mathrm{PhSiH}_{3}$ & $\mathrm{n} . \mathrm{r}$ & - \\
5 & $\mathrm{MePh}_{2} \mathrm{SiH}$ & $87 \%$ & $1: 0$
\end{tabular}

${ }^{a}$ Reaction conditions: 1a $(0.25 \mathrm{mmol}), 2 \mathrm{2a}(1.4$ eq. $), \mathrm{Pd}_{2}(\mathrm{dba})_{3}$ (2.5 mol\%), hydrosilane (3 eq.), Fei-Phos (5 mol\%), $\mathrm{N}_{2}$, rt, $48 \mathrm{~h}$. ${ }^{b}$ Isolated yields after silica gel chromatography. ${ }^{c}$ Determined from GC-MS analysis. 

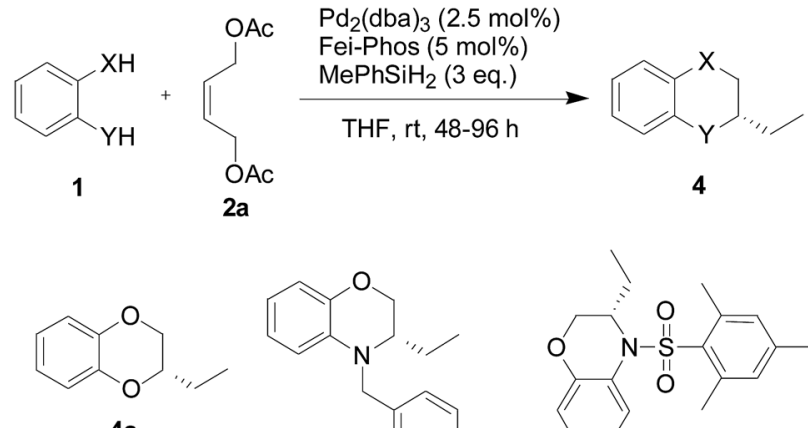

$99 \%$ yield, $45 \%$ ee

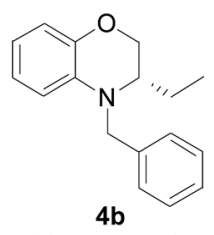

$80 \%$ yield, $46 \%$ ee

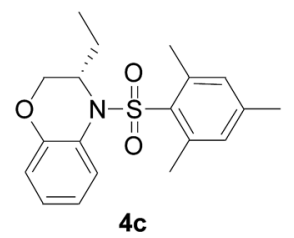

$88 \%$ yield, $11 \%$ ee

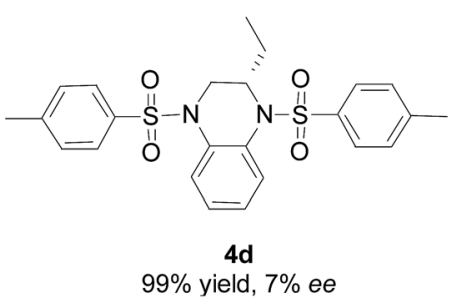

Scheme 3 Palladium-catalyzed multicomponent allylic substitution/ cyclization and cascade reduction with hydrosilane $\left(\mathrm{MePhSiH}_{2}\right)$.

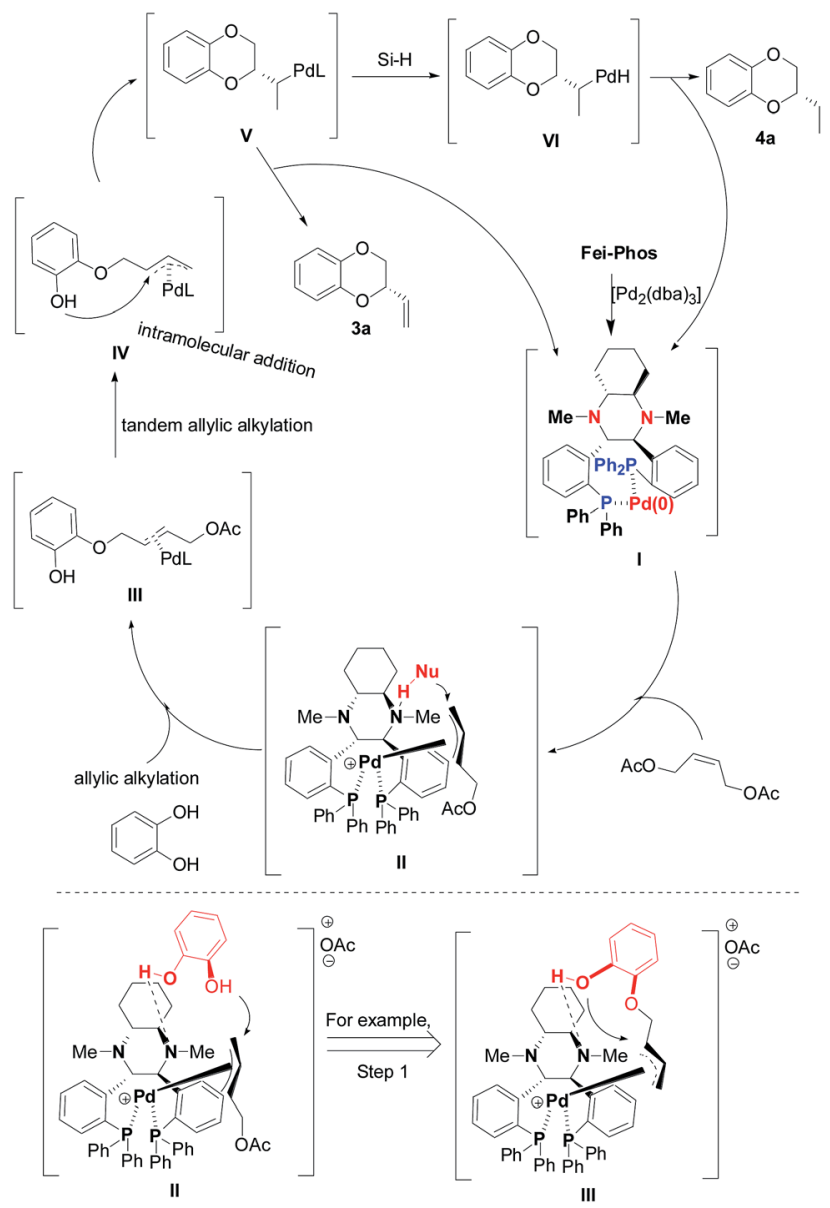

Scheme 4 The proposed mechanism for asymmetric palladiumcatalyzed allylic substitution/cyclization and cascade hydrosilylated reduction in the presence of hydrosilane.
Therefore, we have successfully developed a novel strategy for the asymmetric palladium-catalyzed multicomponent allylic alkylation and one-pot reduction of an alkene product.

Finally, under the optimized reaction conditions that were established, shown in Table 3, the substrate scope of this palladium-catalyzed multicomponent allylic substitution/ cyclization and cascade reduction with hydrosilane $\left(\mathrm{MePhSiH}_{2}\right)$ was examined with the representative 1,2-bifunctional nucleophiles 1. As summarised in Scheme 3, all the corresponding heterocycle products 4 were obtained in excellent yields $(80-99 \%$ isolated yields) with moderate to low enantioselectivities (up to $46 \%$ ee).

On the basis of the experimental results and the generally accepted mechanism for palladium-catalyzed allylic alkylation, ${ }^{18}$ we proposed a mechanistic procedure with the corresponding transition-state model, as shown in Scheme 4. In the first step, there was an initial oxidative addition of the low valent palladium species $\left(\operatorname{Pd}(0) \mathbf{L}_{2}\right)$, which formed in situ from $\operatorname{Pd}_{2}(\mathrm{dba})_{3}$ and FeiPhos, to the (Z)-but-2-ene-1,4-diol derived allylic acetate $2 \mathrm{a}$ (electrophile) and then nucleophilic attack on the corresponding allylic Pd(II) cation. Subsequently, the reductive elimination of the palladium intermediate II that had coordinated with the ligand resulted in the formation of the single alkylation intermediate III, and then intramolecular allylic alkylation led to the regeneration of the $\operatorname{Pd}(0)$ complex when intermediate IV liberated the product.

\section{Conclusions}

In summary, we have determined the stereoselective activity of Fei-Phos in the asymmetric palladium-catalyzed tandem allylic alkylation of 1,2-bifunctional nucleophiles 1 with the ( $Z$ )-but-2ene-1,4-diol derived allylic acetate $\mathbf{2 a}$. In addition, the influence of the reaction parameters on palladium-catalyzed tandem allylic alkylation in the presence of Fei-Phos, including the effect of various phosphine ligands, inorganic or organic bases, Brønsted acids, and other additives on the asymmetric palladium-catalysed alkylation of catechol with allylic diacetate, was investigated in detail. Under optimized reaction conditions, the corresponding 2-vinyl-2,3-dihydro-benzo[1,4]dioxin products were achieved with promising enantioselectivity in good yields. In addition, a novel one-pot allylic substitution/ cyclization and cascade reduction with the aid of methylphenylsilane was further developed in this work. It provides an interesting example of the concept of silicon-mediated organic synthesis (SiMOS) because the three-component reaction is precisely controlled by certain hydrosilanes. Finally, on the basis of the present work, we believe that the modification of Fei-Phos would be an effective strategy for the improvement of asymmetric palladium-catalyzed transformations.

\section{Conflicts of interest}

There are no conflicts to declare.

\section{Acknowledgements}

The authors gratefully thank the National Natural Science Foundation of China (No. 21472031, 21703051, 21702211, and 
21773051), and the Zhejiang Provincial Natural Science Foundation of China (LZ18B020001, LY16E030009, LY17B030005, and LY17E030003) for financial support, which is appreciated. The authors also thank Dr J. Cao, Dr Y. M. Cui, Dr F. Ye, Dr K. Z. Jiang, Dr C. Q. Sheng, and Dr W. G. Yin (all at HZNU) for their technical and analytical support.

\section{Notes and references}

1 (a) B. M. Trost, Acc. Chem. Res., 1980, 13, 385-393; (b) J. Tsuji, I. Minami and I. Shimizu, Chem. Lett., 1983, 1325-1326, and references cited therein.

2 For representative reviews, see: (a) B. M. Trost and M. L. Crawley, Chem. Rev., 2003, 103, 2921-2943; (b) Z. Lu and S. Ma, Angew. Chem., Int. Ed., 2008, 47, 258-297; For representative book, see: $(c)$ D. Caine, in Comprehensive Organic Synthesis, ed. B. M. Trost and I. Fleming, Pergamon, Oxford, 1991, vol. 3, pp. 1-63.

3 For recent examples, see: (a) S. Chang, L. Wang and X. Lin, Org. Biomol. Chem., 2018, 16, 2239-2247; (b) I. Szulc, R. Kolodziuk and A. Zawisza, Tetrahedron, 2018, 74, 14761485; (c) Z. P. Yang, R. Jiang, C. Zheng and S. L. You, J. Am. Chem. Soc., 2018, 140, 3114-3119; (d) Y. J. Yang, G. P. Zhang, J. Q. Huang, D. Chen, C. H. Ding and X. L. Hou, Org. Lett., 2017, 19, 5932-5935; (e) E. J. Alexy, S. C. Virgil, M. D. Bartberger and B. M. Stoltz, Org. Lett., 2017, 19, 5007-5009; $(f)$ L. Wei, S. M. Xu, Q. Zhu, C. Che and C. J. Wang, Angew. Chem., Int. Ed., 2017, 56, 1231212316; ( $g$ ) J. Wang, P. X. Wang, L. Q. Wang, D. Li, K. Z. Wang, Y. Wang, H. Y. Zhu, D. X. Yang and R. Wang, Org. Lett., 2017, 19, 4826-4829; (h) S. Kayal and S. Mukherjee, Org. Lett., 2017, 19, 4944-4947; (i) S. E. Shockley, J. C. Hethcox and B. M. Stoltz, Angew. Chem., Int. Ed., 2017, 56, 11545-11548; (j) P. Starkov, J. T. Moore, D. C. Duquette, B. M. Stoltz and I. Marek, J. Am. Chem. Soc., 2017, 139, 9615-9620.

4 For recent reviews or books: (a) W. Tang and X. Zhang, Chem. Rev., 2003, 103, 3029-3069; (b) Privileged Chiral Ligands and Catalysts, ed. Q. L. Zhou, Wiley-VCH, Singapore, 2011; (c) M. P. Carroll and P. J. Guiry, Chem. Soc. Rev., 2014, 43, 819-833.

5 For recent reviews, see: (a) J. P. Qu and G. Helmchen, Acc. Chem. Res., 2017, 50, 2539-2555; (b) I. G. Rios, A. RosasHernandez and E. Martin, Molecules, 2011, 16, 970-1010; (c) H. Fernández-Pérez, P. Etayo, A. Panossian and A. VidalFerran, Chem. Rev., 2011, 111, 2119-2176. For recent examples, see: (d) J. Q. Huang, W. Liu, B. H. Zheng, X. Y. Liu, Z. Yang, C. H. Ding, H. Li, Q. Peng and X. L. Hou, ACS Catal., 2018, 8, 1964-1972; (e) B. P. Pritchett, E. J. Donckele and B. M. Stoltz, Angew. Chem., Int. Ed., 2017, 56, 12624-12627; $(f)$ M. A. Schafroth, S. M. Rummelt, D. Sarlah and E. M. Carreira, Org. Lett., 2017, 19, 3235-3238; (g) T. Y. Lin, H. H. Wu, J. J. Feng and J. L. Zhang, Org. Lett., 2017, 19, 2897-2900; (h) A. Saito, N. Kumagai and M. Shibasaki, Angew. Chem., Int. Ed., 2017, 56, 5551-5555; (i) Y. Suzuki, N. Vatmurge, S. Tanaka and M. Kitamura, Chem.-Asian J., 2017, 12, 633-637; (j)
J. D. Sieber, V. V. Angeles, D. Chennamadhavuni, D. R. Fandrick, N. Haddad, N. Grinberg, D. Kurouski, H. Lee, J. H. J. Song, N. K. Yee, A. E. Mattson and C. H. Senanayake, Adv. Synth. Catal., 2016, 358, 3062-3068; (k) Q. L. Liu, W. Chen, Q. Y. Jiang, X. F. Bai, Z. Li, Z. Xu and L. W. Xu, ChemCatChem, 2016, 8, 1495-1499.

6 For a representative review on catalytic asymmetric allylic alkylation employing heteroatom nucleophiles, see: (a) B. M. Trost, T. Zhang and J. D. Sieber, Chem. Sci., 2010, 1, 427-440; (b) J. Qu and G. Helmchen, Acc. Chem. Res., 2017, 50, 2539-2555; For recent examples, see: (c) X. Caldentey and M. A. Pericàs, J. Org. Chem., 2010, 75, 2628-2644; (d) M. Austeri, D. Linder and J. Lacour, Adv. Synth. Catal., 2010, 352, 3339-3347; (e) L. Dai, X. Li, H. Yuan, X. Li, Z. Li, D. Xu, F. Lei, Y. Liu, J. Zhang and Z. Zhou, Tetrahedron: Asymmetry, 2011, 22, 1379-1389; (f) M. Roggen and E. M. Carreira, Angew. Chem., Int. Ed., 2011, 50, 5568-5571; (g) K. N. Gavrilov, S. V. Zheglov, A. A. Shiryaev, N. N. Groshkin, E. A. Rastorguev, E. B. Benetskiy and V. A. Davankov, Tetrahedron Lett., 2011, 52, 964-968; (h) W. H. Deng, F. Ye, X. F. Bai, Z. J. Zheng, Y. M. Cui and L. W. Xu, ChemCatChem, 2015, 7, 75-79; (i) C. Xia, J. Shen, D. Liu and W. Zhang, Org. Lett., 2017, 19, 4251-4254; (j) P. Paz and A. Baeza, Adv. Synth. Catal., 2017, 359, 17351741; (k) Y. Suzuki, N. Vatmurge, S. Tanaka and M. Kitamura, Chem.-Asian J., 2017, 12, 633-637; (l) Z. Wu, X. Fang, Y. Leng, H. Yao and A. Lin, Adv. Synth. Catal., 2018, 360, 1289-1295.

7 (a) F. L. Lam, T. T. L. Au-Yeung, F. Y. Kwong, Z. Zhou, K. Y. Wong and A. S. C. Chan, Angew. Chem., Int. Ed., 2008, 47, 1280-1283; (b) M. Kato, T. Nakamura, K. Ogata and S.-I. Fukuzawa, Eur. J. Org. Chem., 2009, 5232-5238; (c) P. Fang, C. H. Ding, X. L. Hou and L. X. Dai, Tetrahedron: Asymmetry, 2010, 21, 1176-1178; (d) Z. Liu and H. Du, Org. Lett., 2010, 12, 3054-3057; (e) J. Mazuela, O. Pàmies and M. Diéguez, Chem.-Eur. J., 2013, 19, 2416-2432; (f) B. Feng, H. G. Cheng, J. R. Chen, Q. H. Deng, L. Q. Lu and W. J. Xiao, Chem. Commun., 2014, 50, 9550-9553; $(g)$ M. Coll, O. Pàmies and M. Diéguez, Org. Lett., 2014, 16, 1892-1895; (h) P. Trillo and I. M. Pastor, Adv. Synth. Catal., 2016, 358, 2929-2939; (i) A. Khan, S. Khan, I. Khan, C. Zhao, Y. Mao, Y. Chen and Y. J. Zhang, J. Am. Chem. Soc., 2017, 139, 10733-10741.

8 F. Ye, Z. J. Zheng, L. Li, K. F. Yang, C. G. Xia and L. W. Xu, Chem.-Eur. J., 2013, 19, 15452-15457.

9 (a) J. X. Xu, F. Ye, X. F. Bai, Y. M. Cui, Z. Xu, Z. J. Zheng and L. W. Xu, RSC Adv., 2016, 6, 70624-70631; (b) J. X. Xu, F. Ye, X. F. Bai, J. Zhang, Z. Xu, Z. J. Zheng and L. W. Xu, RSC Adv., 2016, 6, 45495-45502.

10 (a) M. Massacret, C. Goux, P. Lhoste and D. Sinou, Tetrahedron Lett., 1994, 35, 6093-6096; (b) C. Goux, M. Massacret, P. Lhoste and D. Sinou, Organometallics, 1995, 14, 4585-4593.

11 (a) S. Tanimori, Y. Kato and M. Kirihata, Synthesis, 2004, 2103-2106; (b) K. Ito, Y. Imahayashi, T. Kuroda, S. Eno, B. Saito and T. Katsuki, Tetrahedron Lett., 2004, 45, 72777281; (c) M. Massacret, R. Lakhmiri, P. Lhoste, 
C. Nguefack, A. Ben, B. Fouad, R. Fadel and D. Sinou, Tetrahedron: Asymmetry, 2000, 11, 3561-3568; (d) M. Massacret, P. Lhoste, R. Lakhmiri, T. Parella and D. Sinou, Eur. J. Org. Chem., 1999, 1999, 2665-2673.

12 (a) M. R. Stillings, C. B. Chapleo, R. C. M. Butler, J. A. Davis, C. D. England, M. Myers, P. L. Myers, N. Tweddle, A. P. Welbourn, J. C. Doxey and C. F. C. Smith, J. Med. Chem., 1985, 28, 1054-1062; (b) D. Giardina, R. Bertini, E. Brancia, L. Brasili and C. Melchiorre, J. Med. Chem., 1985, 28, 1354-1357; (c) G. P. Fagan, C. B. Chapleo, A. C. Lane, M. Myers, A. G. LarRoach, C. F. C. Smith, M. R. Stillings and A. P. Welbourn, J. Med. Chem., 1988, 31, 944-948; (d) G. Marciniak, A. Delgado, G. Leclerc, J. Velly, N. Decker and J. Schwartz, J. Med. Chem., 1989, 32, 1402-1407; (e) R. R. Ruffolo Jr, W. Bondinell and J. P. Hieble, J. Med. Chem., 1995, 38, 3681-3716; (f) N. R. Guz and F. R. Stermitz, J. Nat. Prod., 2000, 63, 1140-1145; (g) R. Gazak, K. Valentova, K. Fuksova, P. Marhol, M. Marek, A. Miguel, I. Oborna, J. Jitka and V. Kren, J. Med. Chem., 2011, 54, 7397-7407.

13 For HZNU-Phos (L14): (a) F. Ye, Z. J. Zheng, W. H. Deng, L. S. Zheng, Y. Deng, C. G. Xia and L. W. Xu, Chem.-Asian J., 2013, 8, 2242-2253; For Ar-NNP (L9): (b) L. S. Zheng, L. Li, K. F. Yang, Z. J. Zheng, X. Q. Xiao and L. W. Xu, Tetrahedron, 2013, 69, 8777-8784; For Tao-Phos (L10): (c) T. Song, L. S. Zheng, F. Ye, W. H. Deng, Y. L. Wei, K. Z. Jiang and L. W. Xu, Adv. Synth. Catal., 2014, 356, 1708-1718; (d) T. Song, L. Li, W. Zhou, Z. J. Zheng, Y. Deng, Z. Xu and L. W. Xu, Chem.-Eur. J., 2015, 21, 554558; For Xing-Phos (L13): (e) X. F. Bai, T. Song, Z. Xu, C. G. Xia, W. S. Huang and L. W. Xu, Angew. Chem., Int. Ed., 2015, 54, 5255-5259; For L4: $(f)$ L. Chen, J. B. Huang, Z. Xu, Z. J. Zheng, K. F. Yang, Y. M. Cui, J. Cao and L. W. Xu, RSC Adv., 2016, 6, 67113-67117; For L11: $(g)$ J. X. Xu, M. Y. Chen, Z. J. Zheng, J. Cao, Z. Xu, Y. M. Cui and L. W. Xu, ChemCatChem, 2017, 9, 3111-3116, and references cited therein.
14 J. S. Cannon, A. C. Olson, L. E. Overman and N. S. Solomon, J. Org. Chem., 2012, 77, 1961-1973.

15 The synthesis of $\mathbf{A 8}$ and A9, see: (a) G. Gao, F. L. Gu, J. X. Jiang, K. Jiang, C. Q. Sheng, G. Q. Lai and L. W. Xu, Chem.-Eur. J., 2011, 17, 2698-2703; (b) C. Dong, S. Tao, X. F. Bai, Y. M. Cui, Z. Xu and L. W. Xu, Catal. Sci. Technol., 2015, 5, 4755-4759.

16 (a) X. F. Bai, T. Song, W. H. Deng, Y. L. Wei, L. Li, C. G. Xia and L. W. Xu, Synlett, 2014, 25, 417-422; (b) X. F. Bai, L. W. Xu, L. S. Zheng, J. X. Jiang, G. Q. Lai and J. Y. Shang, Chem.-Eur. J., 2012, 18, 8174-8179.

17 For recent examples, see: (a) S. S. M. Spoehrle, T. H. West, J. E. Taylor, A. M. Z. Slawin and A. D. Smith, J. Am. Chem. Soc., 2017, 139, 11895-11902; (b) K. Kim, Y. Jung, S. Lee, M. Kim, D. Shin and H. Byun, Angew. Chem., Int. Ed., 2017, 56, 6952-6956; (c) S. J. Cho, H. Song, H. Kim, L. Qi, K. Hu, S. Yu, J. Zhu, T. Cheng, X. Wang, J. Chen and H. Wu, Org. Lett., 2017, 19, 218-221; (d) Q. S. Gu and D. Yang, Angew. Chem., Int. Ed., 2017, 56, 5886-5889; (e) K. Hu, L. Qi, S. Yu, T. Cheng, X. Wang, Z. Li, Y. Xia, J. Chen and H. Wu, Green Chem., 2017, 19, 1740-1750; (f) K. Hu, Q. Zhen, J. Gong, T. Cheng, L. Qi, Y. Shao and J. Chen, Org. Lett., 2018, 20, 3083-3087; (g) X. Huang, W. Wu, S. Song, C. Fu and S. Ma, Adv. Synth. Catal., 2016, 358, 2791-2805.

18 (a) L. A. Evans, N. Fey, J. N. Harvey, D. Hose, G. C. LloydJones, P. Murray, A. G. Orpen, R. Osborne, G. J. J. OwenSmith and M. Purdie, J. Am. Chem. Soc., 2008, 130, 1447114473; (b) C. P. Butts, E. Filali, G. C. Lloyd-Jones, P.-O. Norrby, D. A. Sale and Y. Schramm, J. Am. Chem. Soc., 2009, 131, 9945-9957; (c) M. H. Katcher, P.-O. Norrby and A. G. Doyle, Organometallics, 2014, 33, 2121-2133; (d) M. Magre, M. Biosca, P. O. Norrby, O. Pamies and M. Dieguez, ChemCatChem, 2015, 7, 4091-4107; (e) A. J. DeAngelis, P. G. Gildner, R. Chow and T. J. Colacot, J. Org. Chem., 2015, 80, 6794-6813. 